This is a self-archived version of an original article. This version may differ from the original in pagination and typographic details.

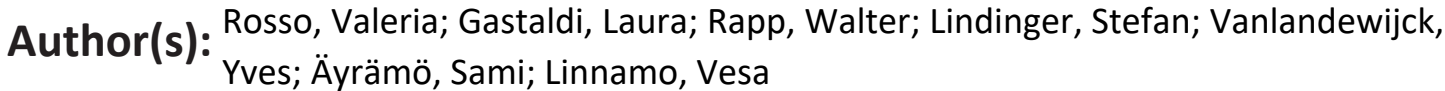

Title: Balance Perturbations as a Measurement Tool for Trunk Impairment in Cross-Country Sit Skiing

Year: 2019

Version: Accepted version (Final draft)

Copyright: ㄷ 2019 HUMAN KINETICS, INC

Rights: In Copyright

Rights url: http://rightsstatements.org/page/InC/1.0/?language=en

Please cite the original version:

Rosso, V., Gastaldi, L., Rapp, W., Lindinger, S., Vanlandewijck, Y., Äyrämö, S., \& Linnamo, V. (2019). Balance Perturbations as a Measurement Tool for Trunk Impairment in Cross-Country Sit Skiing. Adapted Physical Activity Quarterly, 36(1), 61-76. https://doi.org/10.1123/apaq.20170161 


\section{Balance perturbations as a measurement tool for trunk impairment in cross-country sit skiing}

Rosso $\mathrm{V}^{1,2}$, Gastaldi $\mathrm{L}^{1}$, Rapp $\mathrm{W}^{3}$, Lindinger $\mathrm{S}^{4}$, Vanlandewijck $\mathrm{Y}^{5}$, Äyrämö $\mathrm{S}^{6}$, Linnamo $\mathrm{V}^{2}$

${ }^{1}$ Department of Mechanical and Aerospace Engineering, Politecnico di Torino, Italy

2 Biology of Physical Activity, Faculty of Sport and Health Sciences, University of Jyväskylä, Finland

${ }^{3}$ Department of Sport and Sport Science, University of Freiburg, Germany

${ }^{4}$ Department of Food and Nutrition and Sport Science, University of Gothenburg, Sweden

${ }^{5}$ Department of Rehabilitation Sciences, KU Leuven, Belgium

${ }^{6}$ Faculty of Information Technology, University of Jyväskylä, Finland

Corresponding author:

Valeria Rosso

Department of Mechanical and Aerospace Engineering, Politecnico di Torino

Corso Duca degli Abruzzi 24, Torino, Italy

E-mail: valeria_rosso@polito.it 


\section{Abstract}

2 In cross-country sit-skiing, the trunk plays a crucial role in propulsion generation and balance

3 maintenance. Trunk stability is evaluated by automatic responses to unpredictable

4 perturbations; however electromyography is challenging. The aim of this study is to identify a

5 measure to group sit-skiers according to their ability to control the trunk. Seated in their

6 competitive sit-ski, ten male and five female Paralympic sit-skiers received six forward and

7 six backward unpredictable perturbations in random order. k-means clustered trunk position

8 at rest, delay to invert the trunk motion, and trunk range of motion significantly into two

9 groups. In conclusion, unpredictable perturbations might quantify trunk impairment and may

10 become an important tool in the development of an evidence-based classification system for

11 cross-country sit-skiers.

12

13

14

15

16

17

18

19 Key words: Core stability; Automatic responses; Spinal cord injury; Paralympics, k-means. 


\section{Introduction}

22 Paralympic cross-country $(\mathrm{XC})$ sit skiing is a Paralympic discipline in which athletes are

23 skiing seated because they have an impairment in function or structure of the lower 24 extremities, pelvis and/or trunk. XC sit-skiers ski using a sledge mounted on a pair of XC

25 skis, named sit-ski, and a couple of poles to generate propulsion. To guarantee a fair 26 competition, in Paralympic events, seated athletes are divided into five different classes (LW 27 [locomotor winter] 10, 10.5, 11, 11.5, 12) reflecting a lower impact of the athlete's 28 impairment on XC-skiing performance (International Paralympic Committee, 2014). In order to achieve maximal performance, an athlete needs to effectively generate

30 propulsion force by means of a symmetrical double poling action and to maintain the balance

31 on the sit-ski during pushing, in downhills and various curves. A common factor that impacts on both propulsion generation and balance maintenance is the athlete's ability to control the trunk. The complex role of the trunk in generating propulsion can be subdivided in three main

34 contributing components: trunk momentum, trunk position, and trunk stability. An adequate use of trunk flexion and extension transfers the trunk momentum to the ski poles increasing the propulsive force component. However, in athletes with severe impairment of the lower trunk (LW10), sledge propulsion is mainly initiated by the inertial effect of the upper body region (head and arms) (Gastaldi, Mauro, \& Pastorelli, 2016). The trunk position and its

39 range of movement influence the effectiveness of the trunk momentum (Vanlandewijck,

40 Theisen, \& Daly, 2001). During the pushing phase athletes with minimal impairment (LW12)

41 showed more forward trunk position and lower angle of poles to the ground, which would

42 lead to more effective propulsive forces (Gastaldi, Pastorelli, \& Frassinelli, 2012; Schillinger,

43 Rapp, Hakkarainen, Linnamo, \& Lindinger, 2016). During the recovery phase, LW12 athletes

44 moved their trunk up to bend it down in the subsequent pushing phase (Gastaldi et al., 2012)

45 taking advantage in transferring force to the poles. Skiing on the ergometer, which highly 
46 reproduces skiing on snow (Rosso et al., 2017), athletes LW12 showed more forward trunk

47 position and had higher trunk range of motion (ROM) than athletes with more severe trunk

48 impairment, who kept their trunk closer to the vertical (Rosso et al., 2016). The trunk plays

49 also a major role in maintaining athlete's stability for a proper balancing on the sit-ski while

50 skiing. Trunk stability can be defined as the equilibrium recovery after a perturbation

51 (Zazulak, Hewett, Reeves, Goldberg, \& Cholewicki, 2007) and requires complex muscle

52 coordination (Bergmark, 1989). Trunk stability can be achieved by increasing hip and trunk

53 muscle stiffness, co-contracting the hip and trunk anterior and posterior muscles (Vera-

54 Garcia, Brown, Gray, \& McGill, 2006; Willson, Dougherty, Ireland, \& Davis, 2005) and can

55 be improved by strengthening the core muscles (Hibbs, Thompson, French, Wrigley, \&

56 Spears, 2008). Although trunk stability can be improved by strengthening the core muscles;

57 athletes with high impact of impairment, such as athletes LW10, cannot increase trunk

58 stiffness and the balance control while skiing. To overcome reduced hip and trunk muscular

59 control and improve the stability on the sit-ski, these XC sit-skiers adopt a sitting position

60 with the hips lower than the knees (knee high position) which assures low trunk ROM

61 (Gastaldi et al., 2012) and limited trunk momentum. In contrast, a kneeing position with the

62 hips higher than the knees is usually adopted by athletes with good trunk control to get

63 benefit from increased trunk ROM and to control the force direction in order to increase the

64 horizontal component.

65 Given the important role of the trunk in XC-skiing propulsion generation and balance

66 maintenance, it is crucial to identify valid impairment measurements to evaluate the ability to

67 control the trunk. A widely used method to assess the ability to control the trunk is to give

68 unpredictable balance perturbations to the support surface. Therefore, inertial forces move the

69 center of mass from the equilibrium position and induce reactive responses, which tend to

70 regain the equilibrium position (Borghuis, Hof, \& Lemmink, 2008; Horak, Henry, \& 
71 Shumway-Cook, 1997; Nashner, 1976; Thigpen et al., 2009). In such a test, the automatic

72 postural responses of the core muscles activation are usually measured (Enoka, 2008; Jones,

73 Henry, Raasch, Hitt, \& Bunn, 2012). In people with damage to proprioceptive tissue in the

74 lumbar spine, a correlation was found between the trunk muscle response time and the

75 balance performance, suggesting that longer muscles activation latency may contribute to

76 impaired trunk control (Borghuis et al., 2008; Cholewicki et al., 2002; Radebold, Cholewicki,

77 Polzhofer, \& Greene, 2001). The recruitment pattern is also altered inducing a loss of

78 stability (Borghuis et al., 2008; Comerford \& Mottram, 2001; Radebold, Cholewicki, Panjabi,

$79 \&$ Patel, 2000). The core muscle response is assessed by using electromyography; however

80 this technique is quite demanding for practical issue (Borghuis et al., 2008), especially in

81 people with spinal cord injury. An alternative method for assessing trunk stability during a

82 sitting balance task is to evaluate reactions to perturbations of the center of pressure

83 (Hendershot \& Nussbaum, 2013; Thrasher et al., 2010).

84 In the present study, a perturbation device was used to move towards a kinematic

85 quantification of trunk stability in people with physical impairment. Kinematic results were

86 used in order to answer the following questions: (a) Do sit-skiers, positioned and strapped as

87 in competition, perform different in a perturbation test? and (b) Is a clustered perturbation

88 outcome compatible with the current classes of the athletes?

\section{$89 \quad$ Method}

\section{Participants}

91 Fifteen elite Paralympic XC sit-skiers (10 male and 5 female, $30 \pm 6$ years, $168 \pm 19 \mathrm{~cm}, 59 \pm$ $9211 \mathrm{~kg}$ ) with different health disorders (spinal cord injury $\mathrm{n}=8$, spina bifida $\mathrm{n}=2$, amputee $\mathrm{n}=5$ )

93 and classes $(\mathrm{LW} 10=2$, LW10.5 $=1$, LW11 $=3$, LW11.5 = 4, LW12 $=5$ ) volunteered as

94 participants. Athletes had been informed about the aim of the tests and the details of the

95 process and signed an informed consent. Participants were free to abandon the tests at any 
moment. The research methods and the protocols were standard and have been approved by

97 the ethics committee of the University of Jyväskylä. The procedures were performed in

98 accordance with the Declaration of Helsinki.

99 Overall design and experimental setup

100 All the tests were conducted during the IPC World Cup in December 2014 in Vuokatti,

101 Finland. The set up consisted of a motorized plate ( $0.94 \mathrm{~m}$ long and $0.84 \mathrm{~m}$ wide) on which

102 the athlete's sit-ski was fixed using four clamps as it is shown in Figure 1A (University of

103 Jyväskylä, Finland). The plate was driven by an electro-mechanical servo-actuator (IndraDyn

104 S MSK, Bosh Rexroth, Lohr am Main, Germany) along a couple of parallel tracks $1.4 \mathrm{~m}$ long

105 (Figure 1B). The plate was controlled by a LabVIEW custom-made script (LabVIEW 8.5;

106 National Instruments, Austin, Texas, USA). The maximum acceleration and maximum

107 velocity were set at $\pm 2.5 \mathrm{~m} / \mathrm{s}^{2}$ and $\pm 0.5 \mathrm{~m} / \mathrm{s}$ respectively. The direction and the duration of

108 each stimulus were arbitrary decided by the operator. A maximum of two perturbations in the

109 same direction were allowed because of the length of the tracks.

113 The protocol consisted of twelve unpredictable balance perturbations (6 forward and 6

114 backward, in antero-posterior direction) while athletes were sitting on their personal sit-ski strapped as for a competitive event. According to the rules and regulation document (International Paralympic Committee, 2016), maximum sitting height (between the top of the

117 cushion and the top of the ski) was $40 \mathrm{~cm}$; however athletes may use lower sledges.

118 Perturbations were given in random order with varying inter-trial intervals to prevent athletes

119 from anticipating platform movements, which affects the perturbation response (Gilles, 120 Wing, \& Kirker, 1999). Athletes were instructed to keep the upper limbs in a neutral position 
121

122

123

124

125

126

127

128

129

130

131

132

133 onset of the shoulder acceleration, and when the trunk inverted the motion. The time span of

$143150 \mathrm{~ms}$ was chosen since it represents the interval of possible reflex contribution before 144 voluntary activation (Enoka, 2008), considering the electromechanical delay (Cavanagh \&

and maintain the stability as much as possible during the perturbation. Time was given to athletes to recover the initial position on the sit-ski before the following perturbation was initiated.

A motion analysis system composed of 8 Vicon cameras and the Vicon Nexus software (Vicon Motion Systems Ltd., Oxford, UK) was used to register trunk movements. A passive reflective marker was fixed on the posterior right corner of the plate. In addition, five markers were placed on the right side of each athlete; on the shoulder (acromion), the elbow (lateral epicondyle), the wrist (ulnar styloid process), on the hip (great trochanter), and on the knee (lateral epicondyle). When the sit-ski seat did not allow fixing the marker directly on the hip, the marker was fixed on the sit-ski in correspondence to the great trochanter. In this study, only the acromion and hip markers were used to evaluate trunk angle with respect to a vertical line (trunk angle). The trunk movement onset was identified as an increase in the acceleration of the acromion marker along the anteroposterior direction.

\section{Temporal variables}

To assess the temporal response to unpredictable balance perturbations, two different delays were calculated for each stimulus: the delay between the onset of the sledge acceleration and the onset of the shoulder acceleration (DLY $)_{1}$ and the delay between the onset of the shoulder acceleration and the time when the trunk inverted the motion (DLY $)$.

\section{Kinematic variables}

To evaluate the kinematic response, the trunk ROM was assessed. The trunk angle was calculated at three specific times: at rest before the first stimulus (REST), $150 \mathrm{~ms}$ after the 
145 Komi, 1979; Howatson, Glaister, Brouner, \& van Someren, 2009; Szpala, Rutkowska-

146 Kucharska, \& Drapala, 2014). Trunk flexions and extensions are reported positive and

147 negative, respectively. For each perturbation two trunk ROMs were calculated: ROM $_{150}$

148 between REST and $150 \mathrm{~ms}$, and $\mathrm{ROM}_{\text {inv }}$ between REST and when the trunk inverted the

149 motion.

150 For each athlete, temporal and kinematic results for the six forward stimuli were averaged;

151 the same was done for the backward stimuli.

152 Cluster Analysis

153 The first step dealt with data preprocessing and variables selection. The data was checked for

154 outliers using the method of the mean plus or minus three standard deviations. The

155 coefficients of variability for temporal and kinematic variables were calculated to select those

156 variables to be considered for the subsequent cluster analysis.

157 In a second step, a k-means cluster analysis was performed in order to empirically group

158 athletes according to their ability to control the trunk, ensuring minimal difference within a

159 cluster and maximum difference between clusters (Altmann, Groen, Hart, Vanlandewijck, \&

160 Keijsers, 2017). k-means was performed defining distances by means of the squared

161 Euclidean and defining the initial seed by means of the k-means++ algorithm. Since the

162 variables were measured in different scales, they were normalized using the z-score. k-means

163 method requires a defined number of clusters $(\mathrm{k})$ a priori or it can be estimated from data.

164 The third step was the cluster analysis validation using both internal and external criteria.

165 Model selection for choosing the optimal number of clusters was performed using an internal

166 validation criterion, Silhouette (Rousseeuw, 1987), which is a data-based index that measures

167 both cluster tightness and separation. The number of clusters was a priori hypothesized to be

1683 in order to divide athletes according to their impairment level in low, middle, and high (i.e.

169 full, partial, or no trunk control). The k-means was run with different values of $\mathrm{k}$ (in a range 
170 between 2 and 4) and the mean silhouette for each model was calculated. The number of

171 clusters $\mathrm{k}$ used for the analysis was identified as the peak in the mean silhouette. The current

172 classes of the athletes were used as external criterion to compare clustering results to a priori

173 information (Xu \& Wunsch, 2008). However, it should be remembered that the current

174 classification is not evidence based and thus it does not represent a gold standard.

175 In the fourth step, Mann-Whitney test was applied to the clustering input variables in order to 176 assess how strongly they contribute to the discrimination between the clusters and, thereby, 177 evaluate their relevance to the new model. The effect size was calculated as correlation 178 coefficient $r$ (Tomczak \& Tomczak, 2014) to determine the meaningfulness of the strength.

179 Statistical significance was set at $\mathrm{p}<0.05$ for all analyses.

180 The analyses and the statistics were performed using custom-made code prepared in MatLab 181 Software (MatLab and Release 2015, The MathWorks, Inc., Natick, Massachusetts, United 182 States).

183 Results

184 During the perturbation stimuli, the plate movements ranged between $15 \mathrm{~cm}$ to $30 \mathrm{~cm}$ and in 185 all cases the athletes were able to invert the trunk motion before the sledge stopped moving. 186 For all athletes, forward perturbations induced a backward trunk motion, while backward 187 perturbation moved the trunk forward.

188 The results for REST, DLY $, \mathrm{DLY}_{2}, \mathrm{ROM}_{150}$, and $\mathrm{ROM}_{\mathrm{inv}}$ are reported as mean \pm standard 189 deviation in Table 1 for all athletes in both forward and backward perturbations. For each 190 athlete, the reported values are the average value of 12 perturbations for REST and 6 191 perturbations for the other variables. 
First step: data preprocessing and variables selection

196 No outliers were identified in the dataset. Coefficients of variability for DLY (forward) and

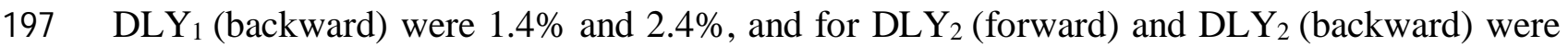

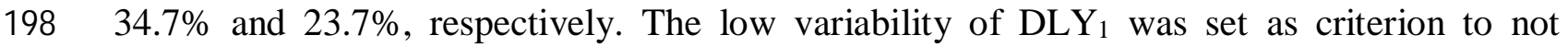
199 consider this variable for the applied cluster analysis. On the contrary variables DLY, $200 \mathrm{ROM}_{150}$, and $\mathrm{ROM}_{\text {inv }}$ in both forward and backward directions were considered for the 201 cluster analysis.

202 Second and third steps: $k$-means analysis and clusters validation

203 The k-means was run with two to four clusters. Internal validation criterion (Silhouette)

204 results are given in figure 2. Even though three clusters would be the optimal number in order 205 to divide athletes in full, partial, and no trunk control; the highest silhouette was reached for a 206 number of clusters equals to 2 (mean silhouette $=0.52$ ). According to the highest silhouette 207 the athletes were divided in 2 clusters: high and low impact of impairment.

211 Results for the external validation criterion were reported in the confusion matrix (Table 2).

212 An agreement equal to $80 \%$ was found between the two identified clusters (cluster 1 with 213 high impact of impairment and cluster 2 with low impact of impairment) and the real 214 athletes' classes (group 1: LW10 - LW10.5 - LW11 and group 2: LW11.5 - LW12). In addition, sensitivity equal to $67 \%$ and $89 \%$ was found for group 1 and group 2 respectively and precision equal to $80 \%$ for both clusters. 
221 For all variables, the means \pm standard deviation for both clusters and their relevance to the 222 new model are reported in Table 3, Figure 3, and Figure 4.

226 Three of the selected variables were of most importance in determining the clusters (Table 3).

227 Concerning the temporal variables, $\mathrm{DLY}_{2}$ was higher for cluster 1 in both forward $(\mathrm{p}=0.003$, $228 \mathrm{r}=0.77)$ and backward $(\mathrm{p}=0.01, \mathrm{r}=0.64)$ directions (Figure 3).

Regarding the kinematic variables, REST $(\mathrm{p}=0.006, \mathrm{r}=0.71)$ and trunk $\mathrm{ROM}_{\mathrm{inv}}$ in both forward $(\mathrm{p}=0.02, \mathrm{r}=0.59)$ and backward $(\mathrm{p}=0.004, \mathrm{r}=0.74)$ perturbations were higher for directions was not important in determining the clusters.

Discussion

240 Considering the determinant role of the trunk in propulsion generation and balance

241 maintenance in XC sit-skiing, the aim of this study was twofold: (a) Do sit-skiers, sitting as in 242 competitive events, perform perturbation test differently?, and (b) Is the clusters outcome 243 from the perturbation test coherent with the actual classes of the athletes? The variables 
244 collected in perturbation test: trunk angle at rest, time to invert the trunk motion, and trunk $245 \mathrm{ROM}$ at the inversion significantly divided athletes into two clusters (cluster 1 with high 246 impact of impairment and cluster 2 with low impact of impairment). The clusters matched the 247 actual classification of the athletes in $80 \%$ of the cases.

At rest, the effect size was equal to $71 \%$ (Table 3) suggesting the meaningful effects of this variable in grouping athletes according to their impact of impairment. Athletes with low impact of impairment (cluster 2) had the trunk very close to the vertical (-1.4 deg, Figure 4). This posture is typical of kneeing position, because of the voluntary control of core muscles. In contrast, athletes with high impact of impairment (cluster 1) had on average a more extended trunk position (-11.6 deg). This posture is common in knee high position, to limit the trunk range of motion and to stabilize the trunk between the sit-ski backrest and the thighs (Rapp, Lappi, Lindinger, Ohtonen, \& Linnamo, 2014). In this study athletes used their own sit-ski strapped as for a competitive event to better simulate a realistic skiing situation. and the trunk ROM during backward perturbations $(r=0.74)$ had meaningful effects than the same variables in the opposite stimuli directions (Table 3). Athletes with low impact of impairment (cluster 2) showed a 52\% and $40 \%$ shorter delay to invert the trunk motion (Figure 3) and 28\% and 53\% lower trunk ROM in forward and backward perturbations respectively (Figure 4). The shorter delay and the smaller trunk ROM registered at the inversion of the trunk motion in cluster 2 compared to cluster 1 could be due to faster and stronger neuromuscular activation. Co-contraction of trunk muscles plays a major role in increasing the trunk strength and stiffness and therefore, to assist trunk passive stabilizer, such as bones and ligaments (Borghuis et al., 2008; Panjabi, 1992). Trunk muscles include abdominal and back muscles. Abdominal muscles, especially Transversus Abdominis and 
269 Nadler, 2004; Borghuis et al., 2008). From the back side the Erector Spinae, which spans 270 many spinal segments, provides general trunk stabilization and balance external loads 271 (Bergmark, 1989; Borghuis et al., 2008). Athletes with high impact of impairment have a 272 limited or absent voluntary control of these muscles, which may explain the longer delay to 273 invert the trunk motion and the greater trunk ROM at the inversion.

274 Other than the voluntary muscle activation to increase the trunk stiffness, the reflex 275 contributes up to $42 \%$ in stabilizing the trunk (Moorhouse \& Granata, 2007). In people with 276 spinal cord injury, the reflex arc is intact below the lesion level (Crewe \& Krause, 2009; 277 Ditunno, Little, Tessler, \& Burns, 2004). Because of the disrupted connection to the brain 278 (supraspinal pathways), the lack of inhibition might evoke a hypertonic response (Mukherjee 279 \& Chakravarty, 2010). This might explain why no differences in trunk range of movement 280 were observed after $150 \mathrm{~ms}$, explaining why the reflex component had no meaningful effects 281 in divided athletes in the two clusters (Table 3). Comparing the two perturbation directions, both clusters needed a longer time to invert 283 the trunk motion and had greater trunk ROM in backward than in forward perturbations. This 284 could suggest that perturbations in backward direction are more challenging to be managed 285 than forward with the used perturbation setup and perturbation parameters of acceleration and velocity. Athletes were tested in their own sit-ski, which was equipped with a backrest in 287 those in the knee-high position. The backrest may support athletes during forward 288 perturbations facilitating the trunk inversion and thus reducing the ROM. Overall, due to fine 289 postural adjustment in the sagittal plane, perturbation in anterior-posterior direction may be 290 the best to discriminate between healthy individuals and those with low back pain (Radebold 291 et al., 2001). In particular, a previous study showed that voluntary forward trunk movement 292 can better predict stability limits in individuals with spinal cord injury (Gauthier et al., 2012). 
The second question regarded coherence between the clusters outcome from the

294 perturbation test and the actual classification of the athletes. Analyses were done for k equal

to 2 because of the highest mean silhouette; however the mean silhouette for k equal to 3 was

high too. The possibility to consider three clusters would also be interesting as it would

297 divide athletes among total, partial, and no trunk control; nevertheless, considering only two

298 clusters allowed dividing athletes in significant clusters according to their trunk control.

299 Lower number of clusters compared to what expected could be due to the small sample size,

300 which should be increased in future studies maybe including athletes with comparable

301 impairment who practice similar sports. Actual results showed accuracy between clusters and

302 the current classes of $80 \%$, very high precision in defining clusters $(80 \%)$ and high to very

303 high sensitivity for both groups (67\% and $89 \%$ for group 1 and group 2, respectively). These

304 results were very good considering that the current classification system is not evidence-

305 based. In order to contribute to the development of evidence-based classification, future

306 research should compare perturbation test results with sport-specific measurements, such as

307 poling force generation and the effectiveness of taking a curve.

308 In general the findings are well in line with other sports where the trunk momentum is

309 expected to be greater for those athletes who can control the trunk. A transfer of momentum

310 was previously found in wheelchair racing, in which athletes increased propulsive force by

311 imparting trunk momentum to the handrim (Cooper, 1990). During the recovery phase

312 wheelchair racers move their trunk up vertically, in order to exploit the gravity acceleration

313 during the subsequent pushing phase increasing the force applied to the handrim and enhance

314 propulsion (O'Connor, Robertson, \& Cooper, 1998). In wheelchair racing, also a more

315 anterior position of the trunk is adopted. Moving the trunk forward allows athletes to apply

316 the force beyond the top of the handrim, diminishing the trunk horizontal reaction force

317 (Gehlsen, Davis, \& Bahamonde, 1990), but enhancing the trunk vertical reaction force 
318 (Sanderson \& Sommer, 1985). The trunk vertical reaction force can be countered by the 319 impact of the gravity on the trunk and some residual abdominal muscle strength (Sanderson $320 \&$ Sommer, 1985).

\section{$321 \quad$ Limitations}

322 A limitation of this study is the small sample size. It would be important to get a 323 representative number of athletes with different impairment levels to corroborate actual 324 results and to verify if the highest mean silhouette would increase. Overall the number of elite 325 athletes who compete in XC sit skiing is low and this will be a challenge also in all future 326 studies. One possibility would be to invite athletes with physical impairment (spinal cord 327 injury and amputation) from other but similar sports to increase the sample. Using athletes' 328 own sit-ski during the test allows assessing their movement competitions; however 329 perturbations responses are influenced by both neuromuscular factors as well as sitting 330 constraints. Indeed, sitting constrains such as sit-ski backrest and straps may enhance 331 athletes' stability reducing the trunk ROM and limiting the necessity of control abilities. 332 Performing the test using a standard sitting position and binding for all athletes would allow 333 excluding sitting constrains effects on athletes' responses to unpredictable perturbations.

334 Moreover, the standard sitting position for all athletes would allow fixing markers directly on 335 the joints for all athletes, instead of on the sit-ski seat, increasing the precision in marker 336 positioning. In addition, since the athletes' sitting height and athletes' trunk length were not 337 always the same, the height of the center of mass was not similar. Although no differences 338 were observed between clusters in the time between the onset of the sledge and shoulder 339 acceleration or within the $150 \mathrm{~ms}$ after shoulder acceleration, the height of the center of mass 340 could have affected the inversion of the trunk and this should be taken into account in future 341 studies. 
343 This study aimed to assess if sit-skiers equipped as in competition perform different on a

344 perturbation test and if the clustered perturbation outcome is coherent with the actual 345 athletes' classification. The skier-specific perturbation test showed very high accuracy,

346 sensitivity, and precision in clustering sit-athletes by using variables such as time to stop the

347 trunk and the trunk ROM.

348 Despite some limitations, the unpredictable balance perturbations test together with cluster 349 analysis appears to be a promising addition for the evidence-based classification process in 350 the future because it seems to group the athletes in a valid way due to their impairment level.

351 Therefore, the suggestion for a further study would be testing this clustering method while 352 athletes are sitting in a position not compensated by straps and comparing results with sport353 specific measurements. This suggestion would also allow inviting athletes with spinal cord 354 injury and amputee from other but similar sports to increase the sample size.

\section{Acknowledgement}

356 The authors would thank Magdalena Karczewska-Lindinger, Anna Madej, Marie Ohlsson, 357 Xinyi Ji, Olli Ohtonen and the University of Jyväskylä staff for the technical support; athletes 358 for participating; Fondazione CRT VivoMeglio project, Finnish Ministry of Education and 359 Culture and IPC for approving this research and for financial support. The authors report no 360 conflict of interest.

\section{$361 \quad$ References}

362 Akuthota, V., \& Nadler, S. F. (2004). Core strengthening. Archives of Physical Medicine and Rehabilitation, 85, 86-92.

364 Altmann, V. C., Groen, B. E., Hart, A. L., Vanlandewijck, Y. C., \& Keijsers, N. L. W. 
(2017). Classifying trunk strength impairment according to the activity limitation caused in wheelchair rugby performance. Scandinavian Journal of Medicine and Science in Sports. http://doi.org/10.1111/sms.12921

Bergmark, A. (1989). Stability of the lumbar spine. A study in mechanical engineering. Acta Orthopaedica Scandinavica. Supplementum, 230, 1-54.

Borghuis, J., Hof, A. L., \& Lemmink, K. A. P. M. (2008). The importance of sensory-motor control in providing core stability: Implications for measurement and training. Sports Medicine, 38(11), 893-916.

Cavanagh, P., \& Komi, P. (1979). Electromechanical delay in human skeletal muscle under concentric and eccentric contractions. European Journal of Applied Physiology and Occupational Physiology, 42(3), 159-163.

Cholewicki, J., Greene, H. S., Polzhofer, G. K., Galloway, M. T., Shah, R. A., \& Radebold, A. (2002). Neuromuscular function in athletes following recovery from a recent acute low back injury. The Journal of Orthopaedic and Sports Physical Therapy, 32(11), 568575.

Comerford, M. J., \& Mottram, S. L. (2001). Movement and stability dysfunction contemporary developments. Manual Therapy, 6(1), 15-26.

Cooper, R. A. (1990). Wheelchair racing sports science: a review. Journal of Rehabilitation Research and Development, 27(3), 295-312.

Crewe, N., \& Krause, J. (2009). Spinal cord injury. In Medical, Psychosocial and Vocational Aspects of Disability (3rd ed., pp. 289-303). Publisher Elliott \& Fitzpatrick, Inc. Athens, Greece. 
Ditunno, J. F., Little, J. W., Tessler, A., \& Burns, A. S. (2004). Spinal shock revisited: a fourphase model. Spinal Cord, 42, 383-395.

Enoka, R. M. (2008). Neuromechanics of human movement (4th ed.). Human Kinetics, Champaign.

391

392

393

395

396

397

398

399

400

401

402

403

404

405

406

407

408

Gastaldi, L., Mauro, S., \& Pastorelli, S. (2016). Analysis of the pushing phase in Paralympic cross-country sit-skiers - Class LW10. Journal of Advanced Research, 7(6), 971-978.

Gastaldi, L., Pastorelli, S., \& Frassinelli, S. (2012). A Biomechanical Approach to Paralympic Cross-Country Sit-Ski Racing. Clinical Journal of Sport Medicine, 22(1), $58-64$.

Gauthier, C., Gagnon, D., Jacquemin, G., Duclos, C., Masani, K., \& Popovic, M. R. (2012). Which trunk inclination directions best predict multidirectional-seated limits of stability among individuals with spinal cord injury? Journal of Spinal Cord Medicine, 35(5), $343-350$.

Gehlsen, G. M., Davis, R. W., \& Bahamonde, R. (1990). Intermittent velocity and wheelchair performance characteristics. Adapted Physical Activity Quarterly, 7(3), 219-230.

Gilles, M., Wing, A. M., \& Kirker, S. G. B. (1999). Lateral balance organisation in human stance in response to a random or predictable perturbation. Experimental Brain Research, 124(2), 137-144.

Hendershot, B. D., \& Nussbaum, M. A. (2013). Persons with lower-limb amputation have impaired trunk postural control while maintaining seated balance. Gait and Posture, $38(3), 438-442$.

Hibbs, A. E., Thompson, K. G., French, D., Wrigley, A., \& Spears, I. (2008). Optimizing 
Horak, F. B., Henry, S. M., \& Shumway-Cook, A. (1997). Postural perturbations: new insights for treatment of balance disorders. Physical Therapy, 77(5), 517.

Howatson, G., Glaister, M., Brouner, J., \& van Someren, K. (2009). The reliability of electromechanical delay and torque during isometric and concentric isokinetic contractions. Journal of Electromyography and Kinesiology, 19(5), 975-979.

International Paralympic Committee. (2014). IPC Nordic Skiing - Classification Rules and Regulations. Retrieved from http://www.paralympic.org/nordic-skiing/rules-and-

International Paralympic Committee. (2016). IPC Nordic Skiing Rule and Regulations. Retrieved from http://www.paralympic.org/sites/default/files/document/151119115946728_2015_11_19 non-specific low back pain use a trunk stiffening strategy to maintain upright posture. _IPCNS_Rules\%2Band\%2BRegulations.pdf

Moorhouse, K. M., \& Granata, K. P. (2007). Role of reflex dynamics in spinal stability: Intrinsic muscle stiffness alone is insufficient for stability. Journal of Biomechanics, Journal of Electromyography and Kinesiology, 22(1), 13-20. Frontiers in Neurology, 1, 149. 
431 Nashner, L. M. (1976). Adapting reflexes controlling the human posture. Experimental Brain Research, 26(1), 59-72.

433

434

435

436

437

438

439

440

441

442

443

444

445

446

447

448

449

450

451

452

453

O’Connor, T. J., Robertson, R. N., \& Cooper, R. A. (1998). Three-dimensional kinematic analysis and physiologic assessment of racing wheelchair propulsion. Adapted Physical Activity Quarterly, 15(1), 1-14.

Panjabi, M. M. (1992). The Stabilizing System of the Spine. Part I. Function, Dysfunction, Adaptation, and Enhancement. Journal of Spinal Disorders, 5(4), 383-389.

Radebold, A., Cholewicki, J., Panjabi, M., \& Patel, T. (2000). Muscle response pattern to sudden trunk loading in healthy individuals and in patients with chronic low back pain. Spine, 25(8), 947-954.

Radebold, A., Cholewicki, J., Polzhofer, G. K., \& Greene, H. S. (2001). Impaired postural control of the lumbar spine is associated with delayed muscle response times in patients with chronic idiopathic low back pain. Spine, 26(7), 724-730.

Rapp, W., Lappi, T., Lindinger, S., Ohtonen, O., \& Linnamo, V. (2014). Force production, balance control and muscle activation in different sitting position - pilot study for disabled sit sledge cross-country skiers. In E. Müller, J. Kröll, S. J. Lindinger, J. Pfusterschmied, \& T. Stöggl (Eds.), Science and skiing VI (pp. 453-464). Meyer and Meyer sport. Aachen, Germany.

Rosso, V., Gastaldi, L., Rapp, W., Lindinger, S., Vanlandewijck, Y., \& Linnamo, V. (2017). Biomechanics of simulated versus natural cross-country sit skiing. Journal of Electromyography and Kinesiology, 32, 15-21.

Rosso, V., Linnamo, V., Rapp, W., Lindinger, S., Vanlandewijck, Y., \& Gastaldi, L. (2016). Trunk kinematics during cross country sit-skiing ergometry: skiing strategies associated 
to neuromusculoskeletal impairment. In 2016 IEEE International Symposium on

Rousseeuw, P. J. (1987). Silhouettes: A graphical aid to the interpretation and validation of cluster analysis. Journal of Computational and Applied Mathematics, 20, 53-65.

Sanderson, D. J., \& Sommer, H. J. (1985). Kinematic features of wheelchair propulsion. Journal of Biomechanics, 18(6), 423-429.

Schillinger, F., Rapp, W., Hakkarainen, A., Linnamo, V., \& Lindinger, S. (2016). A descriptive video analysis of classified Nordic disabled sit-skiers during the Nordic World Championship 2013. In A. Hakkarainen, V. Linnamo, \& S. Lindinger (Eds.),

Szpala, A., Rutkowska-Kucharska, A., \& Drapala, J. (2014). Electromechanical delay of Science and Nordic Skiing III (pp. 173-179). Jyväskylä: Jyväskylä University Printing abdominal muscles is modified by low back pain prevention exercise. Acta of Bioengineering and Biomechanics, 16(3), 95-102.

Thigpen, M. T., Cauraugh, J., Creel, G., Day, K., Flynn, S., Fritz, S., ... Behrman, A. (2009).

471 Thrasher, T. A., Sin, V. W., Masani, K., Vette, A. H., Craven, B. C., \& Popovic, M. R. (2010). Responses of the trunk to multidirectional perturbations during unsupported Adaptation of postural responses during different standing perturbation conditions in individuals with incomplete spinal cord injury. Gait and Posture, 292(1), 113-118.

474 Tomczak, M., \& Tomczak, E. (2014). The need to report effect size estimates revisited. An overview of some recommended measures of effect size. Trends in Sport Sciences, 1(21), 19-25. 
477 Vanlandewijck, Y., Theisen, D., \& Daly, D. (2001). Wheelchair propulsion biomechanics:

478 implications for wheelchair sports. Sports Medicine (Auckland, N.Z.), 31(5), 339-67.

479 Vera-Garcia, F. J., Brown, S. H. M., Gray, J. R., \& McGill, S. M. (2006). Effects of different $480 \quad$ levels of torso coactivation on trunk muscular and kinematic responses to posteriorly applied sudden loads. Clinical Biomechanics, 21(5), 443-455.

482

Willson, J. D., Dougherty, C. P., Ireland, M. L., \& Davis, I. M. (2005). Core Stability and Its 483 Relationship to Lower Injury. Journal of the American Academy of Orthopaedic

484 Surgeons, 13(5), 316-325.

485

Xu, R., \& Wunsch, D. C. (2008). Clustering. Clustering. Wiley. Hoboken, New Jersey.

486 http://doi.org/10.1002/9780470382776

487

Zazulak, B. T., Hewett, T. E., Reeves, N. P., Goldberg, B., \& Cholewicki, J. (2007). The effects of core proprioception on knee injury: a prospective biomechanical-

489 epidemiological study. American Journal of Sports Medicine, 35(3), 368-373.

490

491 
493 stimuli. Timing variables: $\mathrm{DLY}_{1}(\mathrm{~ms})$, delay between the onset of the sledge acceleration and

494 the onset of the shoulder acceleration; $\mathrm{DLY}_{2}(\mathrm{~ms})$, delay between the onset of the shoulder

495 acceleration and the time when the trunk inverted the motion. Kinematic variables: REST

496 (deg), trunk angle before the perturbation; $\mathrm{ROM}_{150}(\mathrm{deg})$, trunk range of motion $150 \mathrm{~ms}$ after

497 the onset of the shoulder acceleration; $\mathrm{ROM}_{\mathrm{inv}}(\mathrm{deg})$, trunk range of motion when the trunk

498 inverted the motion. Trunk flexions are reported positive, while trunk extensions are reported

499 negative. For each athlete, the values were obtained averaging twelve perturbations for

500 REST, and six stimuli for the other variables.

\begin{tabular}{|c|c|c|c|c|c|c|c|c|c|c|c|c|c|c|c|c|}
\hline & & \multicolumn{15}{|c|}{ Athletes and Classes } \\
\hline \multirow{2}{*}{$\begin{array}{l}\text { Stimuli } \\
\text { type }\end{array}$} & \multirow{2}{*}{ Variable } & 1 & 2 & 3 & 4 & 5 & 6 & 7 & 8 & 9 & 10 & 11 & 12 & 13 & 14 & 15 \\
\hline & & 10 & 10 & 10.5 & 11 & 11 & 11 & 11.5 & 11.5 & 11.5 & 11.5 & 12 & 12 & 12 & 12 & 12 \\
\hline \multirow{5}{*}{ 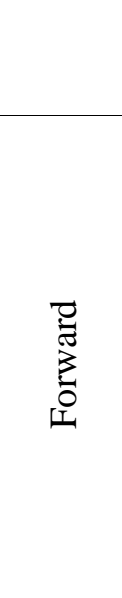 } & $\begin{array}{c}\text { REST } \\
(\mathrm{deg})\end{array}$ & $\begin{array}{l}-18.1 \\
\pm 1.6\end{array}$ & $\begin{array}{l}-11.6 \\
\pm 0.9\end{array}$ & $\begin{array}{l}-4.1 \\
\pm 0.6\end{array}$ & $\begin{array}{l}-6.5 \\
\pm 4.7\end{array}$ & $\begin{array}{l}-11.6 \\
\pm 1.5\end{array}$ & $\begin{array}{l}-7.7 \\
\pm 1.6\end{array}$ & $\begin{array}{l}-10.2 \\
\pm 0.7\end{array}$ & $\begin{array}{c}2.4 \\
\pm 0.9\end{array}$ & $\begin{array}{c}0.3 \\
\pm 1.6\end{array}$ & $\begin{array}{l}-7.4 \\
\pm 0.9\end{array}$ & $\begin{array}{l}-1.1 \\
\pm 0.7\end{array}$ & $\begin{array}{c}2.7 \\
\pm 0.8\end{array}$ & $\begin{array}{l}-6.4 \\
\pm 0.8\end{array}$ & $\begin{array}{c}8.8 \\
\pm 1.5\end{array}$ & $\begin{array}{l}-1.9 \\
\pm 0.8\end{array}$ \\
\hline & $\begin{array}{l}\mathrm{DLY}_{1} \\
(\mathrm{~ms})\end{array}$ & $\begin{array}{c}47 \\
\pm 1.6\end{array}$ & $\begin{array}{c}47 \\
\pm 2.6\end{array}$ & $\begin{array}{c}45 \\
\pm 1.1\end{array}$ & $\begin{array}{c}47 \\
\pm 3.7\end{array}$ & $\begin{array}{c}47 \\
\pm 2.8\end{array}$ & $\begin{array}{c}48 \\
\pm 2.8\end{array}$ & $\begin{array}{c}47 \\
\pm 2.1\end{array}$ & $\begin{array}{c}49 \\
\pm 1.6\end{array}$ & $\begin{array}{c}47 \\
\pm 2.3\end{array}$ & $\begin{array}{c}48 \\
\pm 2.6\end{array}$ & $\begin{array}{c}47 \\
\pm 2.1\end{array}$ & $\begin{array}{c}49 \\
\pm 2.3\end{array}$ & $\begin{array}{c}47 \\
\pm 2.1\end{array}$ & $\begin{array}{c}48 \\
\pm 2.4\end{array}$ & $\begin{array}{c}47 \\
\pm 2.5\end{array}$ \\
\hline & $\begin{array}{c}\mathrm{DLY}_{2} \\
(\mathrm{~ms})\end{array}$ & $\begin{array}{l}338 \\
\pm 88\end{array}$ & $\begin{array}{l}544 \\
\pm 20\end{array}$ & $\begin{array}{l}158 \\
\pm 36\end{array}$ & $\begin{array}{c}359 \\
\pm 168\end{array}$ & $\begin{array}{c}447 \\
\pm 280\end{array}$ & $\begin{array}{l}223 \\
\pm 30\end{array}$ & $\begin{array}{l}321 \\
\pm 45\end{array}$ & $\begin{array}{l}140 \\
\pm 81\end{array}$ & $\begin{array}{r}159 \\
\pm 14\end{array}$ & $\begin{array}{r}107 \\
\pm 3.0\end{array}$ & $\begin{array}{l}258 \\
\pm 96\end{array}$ & $\begin{array}{l}240 \\
\pm 32\end{array}$ & $\begin{array}{l}287 \\
\pm 62\end{array}$ & $\begin{array}{l}167 \\
\pm 10\end{array}$ & $\begin{array}{l}194 \\
\pm 27\end{array}$ \\
\hline & $\begin{array}{c}\mathrm{ROM}_{150} \\
\quad(\mathrm{deg})\end{array}$ & $\begin{array}{l}4.9 \\
0.3\end{array}$ & $\begin{array}{c}6.0 \\
\pm 0.6\end{array}$ & $\begin{array}{c}4.7 \\
\pm 0.4\end{array}$ & $\begin{array}{c}2.0 \\
\pm 4.1\end{array}$ & $\begin{array}{c}5.5 \\
\pm 0.6\end{array}$ & $\begin{array}{c}6.0 \\
\pm 0.4\end{array}$ & $\begin{array}{c}6.0 \\
\pm 0.6\end{array}$ & $\begin{array}{c}2.1 \\
\pm 1.1\end{array}$ & $\begin{array}{c}5.2 \\
\pm 0.1\end{array}$ & $\begin{array}{c}2.8 \\
\pm 0.3\end{array}$ & $\begin{array}{c}5.2 \\
\pm 0.5\end{array}$ & $\begin{array}{c}5.6 \\
\pm 0.2\end{array}$ & $\begin{array}{c}5.3 \\
\pm 0.3\end{array}$ & $\begin{array}{c}6.1 \\
\pm 0.3\end{array}$ & $\begin{array}{c}6.1 \\
\pm 0.4\end{array}$ \\
\hline & $\begin{array}{c}\mathrm{ROM}_{\text {inv }} \\
\quad(\mathrm{deg})\end{array}$ & $\begin{array}{c}5.9 \\
\pm 0.9\end{array}$ & $\begin{array}{c}8.2 \\
\pm 0.7\end{array}$ & $\begin{array}{r}4.8 \\
\pm 0.5\end{array}$ & $\begin{array}{c}9.1 \\
\pm 6.3\end{array}$ & $\begin{array}{c}8.4 \\
\pm 2.4\end{array}$ & $\begin{array}{c}6.8 \\
\pm 0.5\end{array}$ & $\begin{array}{c}8.5 \\
\pm 1.9\end{array}$ & $\begin{array}{c}4.2 \\
\pm 0.7\end{array}$ & $\begin{array}{c}5.2 \\
\pm 0.1\end{array}$ & $\begin{array}{r}4.2 \\
\pm 0.1\end{array}$ & $\begin{array}{c}6.8 \\
\pm 1.7\end{array}$ & $\begin{array}{c}6.2 \\
\pm 0.5\end{array}$ & $\begin{array}{c}6.5 \\
\pm 0.8\end{array}$ & $\begin{array}{r}6.3 \\
\pm 0.5\end{array}$ & $\begin{array}{c}6.6 \\
\pm 0.8\end{array}$ \\
\hline \multirow{4}{*}{ 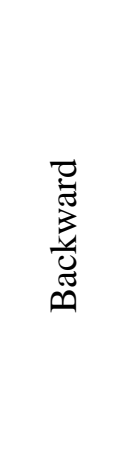 } & $\begin{array}{l}\mathrm{DLY}_{1} \\
(\mathrm{~ms})\end{array}$ & $\begin{array}{c}47 \\
\pm 0.6\end{array}$ & $\begin{array}{c}49 \\
\pm 1.7\end{array}$ & $\begin{array}{c}45 \\
\pm 1.8\end{array}$ & $\begin{array}{c}49 \\
\pm 2.1\end{array}$ & $\begin{array}{c}46 \\
\pm 1.4\end{array}$ & $\begin{array}{c}49 \\
\pm 3.5\end{array}$ & $\begin{array}{c}49 \\
\pm 1.9\end{array}$ & $\begin{array}{c}49 \\
\pm 2.1\end{array}$ & $\begin{array}{c}49 \\
\pm 1.4\end{array}$ & $\begin{array}{c}51 \\
\pm 2.0\end{array}$ & $\begin{array}{c}48 \\
\pm 2.0\end{array}$ & $\begin{array}{c}48 \\
\pm 2.2\end{array}$ & $\begin{array}{c}47 \\
\pm 1.6\end{array}$ & $\begin{array}{c}49 \\
\pm 1.4\end{array}$ & $\begin{array}{c}47 \\
\pm 0.8\end{array}$ \\
\hline & $\begin{array}{c}\mathrm{DLY}_{2} \\
(\mathrm{~ms})\end{array}$ & $\begin{array}{l}698 \\
\pm 71\end{array}$ & $\begin{array}{c}693 \\
\pm 112\end{array}$ & $\begin{array}{l}271 \\
\pm 32\end{array}$ & $\begin{array}{c}651 \\
\pm 124\end{array}$ & $\begin{array}{l}638 \\
\pm 82\end{array}$ & $\begin{array}{l}133 \\
\pm 14\end{array}$ & $\begin{array}{l}443 \\
\pm 48\end{array}$ & $\begin{array}{l}361 \\
\pm 42\end{array}$ & $\begin{array}{l}398 \\
\pm 43\end{array}$ & $\begin{array}{l}333 \\
\pm 61\end{array}$ & $\begin{array}{c}445 \\
\pm 170\end{array}$ & $\begin{array}{l}378 \\
\pm 46\end{array}$ & $\begin{array}{l}357 \\
\pm 31\end{array}$ & $\begin{array}{l}666 \\
\pm 93\end{array}$ & $\begin{array}{r}402 \\
\pm 102\end{array}$ \\
\hline & $\begin{array}{c}\mathrm{ROM}_{150} \\
\quad(\mathrm{deg})\end{array}$ & $\begin{array}{c}5.6 \\
\pm 0.3\end{array}$ & $\begin{array}{c}6.8 \\
\pm 0.6\end{array}$ & $\begin{array}{c}7.3 \\
\pm 0.9\end{array}$ & $\begin{array}{c}4.9 \\
\pm 2.4\end{array}$ & $\begin{array}{c}7.5 \\
\pm 0.4\end{array}$ & $\begin{array}{c}5.8 \\
\pm 0.4\end{array}$ & $\begin{array}{c}6.5 \\
\pm 0.4\end{array}$ & $\begin{array}{c}5.6 \\
\pm 0.3\end{array}$ & $\begin{array}{c}5.8 \\
\pm 0.1\end{array}$ & $\begin{array}{c}6.1 \\
\pm 0.2\end{array}$ & $\begin{array}{c}6.9 \\
\pm 0.2\end{array}$ & $\begin{array}{c}5.7 \\
\pm 0.2\end{array}$ & $\begin{array}{c}5.8 \\
\pm 0.1\end{array}$ & $\begin{array}{c}6.7 \\
\pm 0.3\end{array}$ & $\begin{array}{c}6.5 \\
\pm 0.3\end{array}$ \\
\hline & $\begin{array}{c}\mathrm{ROM}_{\text {inv }} \\
\quad(\mathrm{deg})\end{array}$ & $\begin{array}{l}24.5 \\
\pm 2.4\end{array}$ & $\begin{array}{l}18.8 \\
\pm 6.0\end{array}$ & $\begin{array}{c}8.4 \\
\pm 1.3\end{array}$ & $\begin{array}{l}15.6 \\
\pm 4.5\end{array}$ & $\begin{array}{l}23.4 \\
\pm 2.9\end{array}$ & $\begin{array}{c}6.1 \\
\pm 0.2\end{array}$ & $\begin{array}{l}12.2 \\
\pm 1.1\end{array}$ & $\begin{array}{c}8.9 \\
\pm 0.6\end{array}$ & $\begin{array}{c}8.5 \\
\pm 0.5\end{array}$ & $\begin{array}{c}8.2 \\
\pm 1.0\end{array}$ & $\begin{array}{c}8.9 \\
\pm 0.6\end{array}$ & $\begin{array}{c}8.0 \\
\pm 1.6\end{array}$ & $\begin{array}{c}9.0 \\
\pm 1.0\end{array}$ & $\begin{array}{l}12.3 \\
\pm 1.5\end{array}$ & $\begin{array}{l}10.7 \\
\pm 1.9\end{array}$ \\
\hline
\end{tabular}

501 
503 Table 2. External validation results. The number of elements grouped coherently with the

504 actual classification is reported on the main diagonal of the confusion matrix. For athletes

505 belong to classes from LW10 to LW11 (high level of impairment), the alternative variables

506 grouped four out of six elements coherently with the actual classification; whereas for

507 athletes belong to classed from LW11.5 to LW12 (low level of impairment) athletes

508 coherently grouped are eight out of nine. Therefore, the accuracy is equal to 0.8 , which

509 means that a total of $80 \%$ of athletes are grouped coherently with the actual classification.

\begin{tabular}{|c|c|c|c|c|}
\cline { 2 - 5 } \multicolumn{1}{c|}{} & $\begin{array}{c}\text { Group 1 } \\
\text { (LW10-LW11) }\end{array}$ & $\begin{array}{c}\text { Group 2 } \\
\text { (LW11.5-LW12) }\end{array}$ & Total & Precision \\
\hline $\begin{array}{c}\text { Cluster 1 } \\
\text { (high impairment) }\end{array}$ & 4 & 1 & 5 & $80 \%$ \\
\hline $\begin{array}{c}\text { Cluster 2 } \\
\text { (low impairment) }\end{array}$ & 2 & 8 & 10 & $80 \%$ \\
\hline Total & 6 & 9 & 15 & \\
\hline Sensitivity & $67 \%$ & $89 \%$ & \multicolumn{2}{c}{} \\
\hline
\end{tabular}


512 Table 3. Relevance of variables. The mean \pm the standard deviation were reported for the

513 two clusters on all the selected variables used in the cluster analysis. In addition, it was

514 reported the strength of each variable in contributing to the discrimination between the

515 clusters (Mann-Whitney test results).

\begin{tabular}{|c|c|c|c|c|c|}
\hline $\begin{array}{l}\text { Stimuli } \\
\text { type }\end{array}$ & Variable & Cluster 1 & Cluster 2 & p-value & Effect size \\
\hline & $\begin{array}{l}\text { REST } \\
(\operatorname{deg})\end{array}$ & $-11.6 \pm 4.2$ & $-1.4 \pm 5.2$ & 0.006 & 0.71 \\
\hline \multirow{3}{*}{ 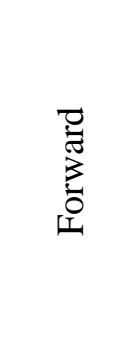 } & $\begin{array}{c}\mathrm{DLY}_{2} \\
(\mathrm{~ms})\end{array}$ & $401.8 \pm 93.2$ & $193.3 \pm 57.3$ & 0.003 & 0.77 \\
\hline & $\begin{array}{c}\mathrm{ROM}_{150} \\
(\mathrm{deg})\end{array}$ & $4.9 \pm 1.7$ & $4.9 \pm 1.4$ & 1 & - \\
\hline & $\begin{array}{c}\mathrm{ROM}_{\text {inv }} \\
(\mathrm{deg})\end{array}$ & $8.0 \pm 1.2$ & $5.8 \pm 1.0$ & 0.02 & 0.59 \\
\hline \multirow{3}{*}{ 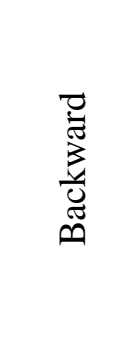 } & $\begin{array}{c}\mathrm{DLY}_{2} \\
(\mathrm{~ms})\end{array}$ & $624.8 \pm 104.6$ & $374.3 \pm 134.3$ & 0.01 & 0.64 \\
\hline & $\begin{array}{c}\mathrm{ROM}_{150} \\
(\mathrm{deg})\end{array}$ & $6.3 \pm 1.0$ & $6.2 \pm 0.6$ & 0.9 & - \\
\hline & $\begin{array}{c}\mathrm{ROM}_{\text {inv }} \\
(\mathrm{deg})\end{array}$ & $18.9 \pm 5.2$ & $8.9 \pm 1.7$ & 0.004 & 0.74 \\
\hline
\end{tabular}




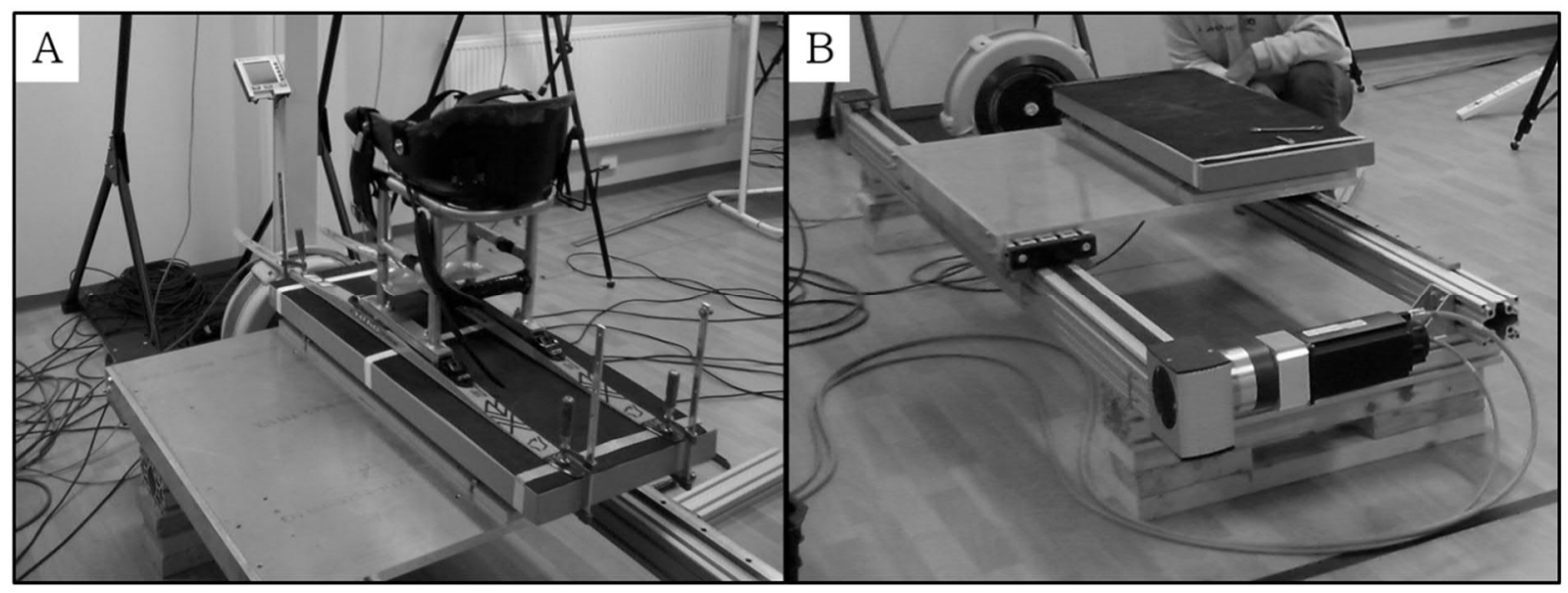

519 Figure 1. Setup used for unpredictable stimuli. (A) Athlete's sit-ski was fixed on a

520 movable plate by four clamps. Athlete was sitting on his/her personal sit-ski strapped as for a

521 competitive event. (B) The movable plate (0.94 $\mathrm{m}$ long and $0.84 \mathrm{~m}$ wide) can be moved along

522 a couple of parallel tracks $1.4 \mathrm{~m}$ long by an electro-mechanic servo-actuator that was

523 controlled by custom-made software. 


\section{Silhouette mean}

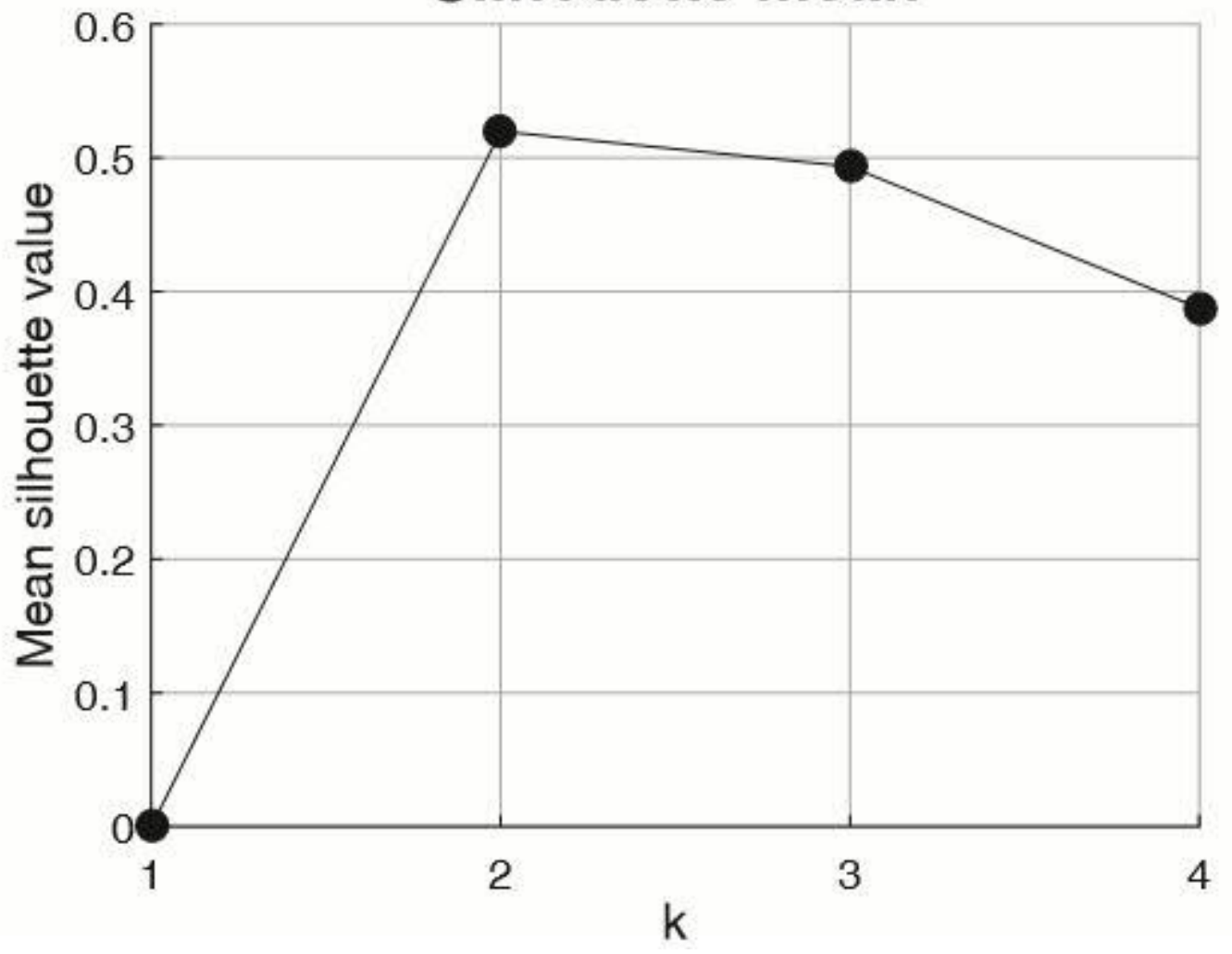

526 Figure 2. Mean silhouette graph. To define the number of clusters (k) for the analysis, the

527 k-means was run with three different k (from 2 to 4) and the mean silhouette for each k was

528 calculated. The $\mathrm{k}=2$ was chosen for the analysis because of it showed the highest mean

529 silhouette value (0.52).

530 


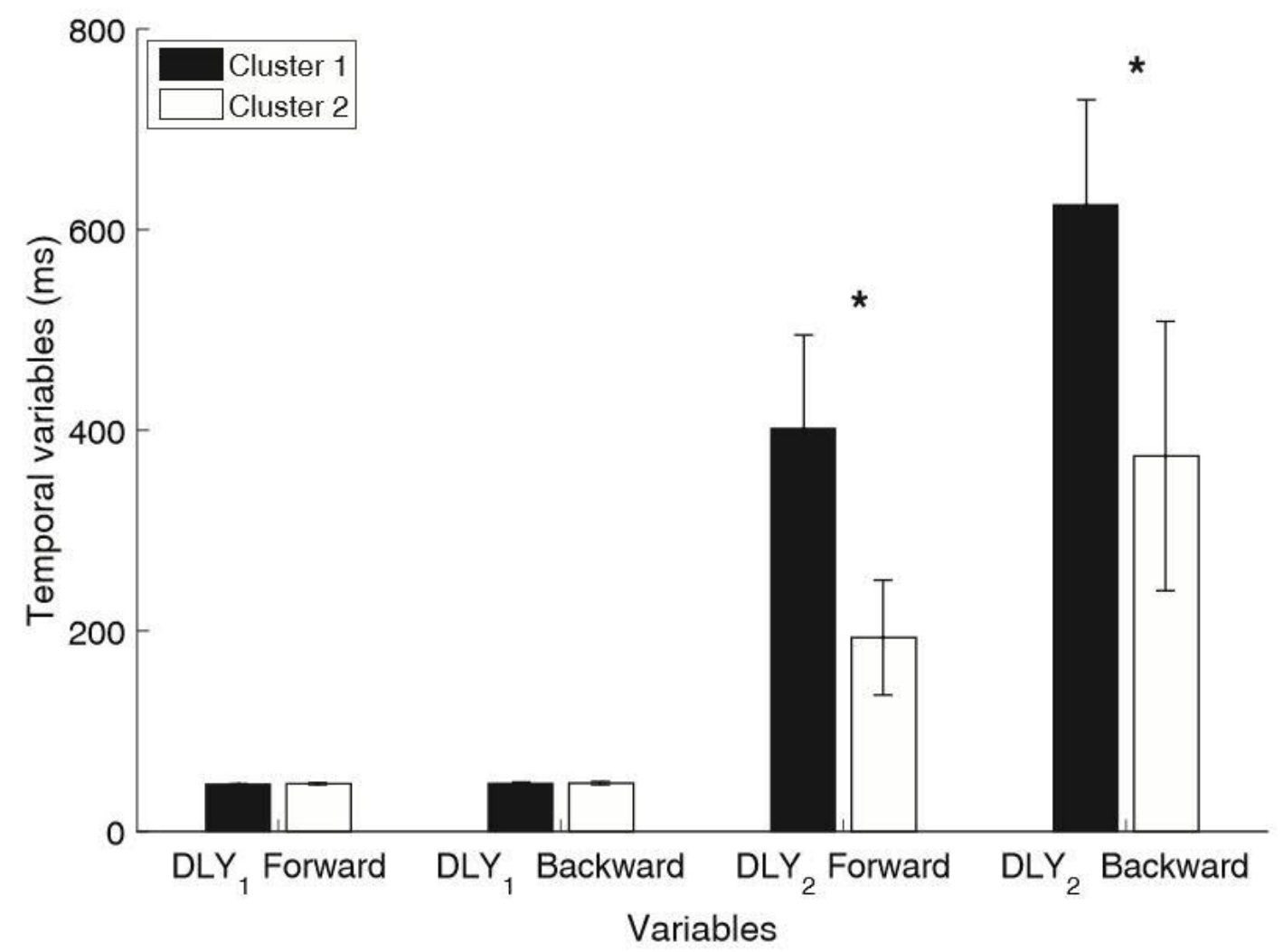

532 Figure 3. Temporal variable. The delay between the onset of the sledge acceleration and the 533 onset of the shoulder acceleration $\left(\mathrm{DLY}_{1}\right)$ and the delay between the onset of the shoulder 534 acceleration and the time when the trunk inverted the motion (DLY $)_{2}$ in both forward and 535 backward perturbations were represented for the two clusters. The DLY2 showed a difference 536 between the two clusters in both forward and backward perturbations (*). Cluster 2 (athletes 537 with low impact of impairment) showed a lower delay in both perturbation directions than 538 cluster 1 (athletes with high impact of impairment). During forward perturbations shorter 539 time was necessary to invert the trunk motion than in backward direction. 


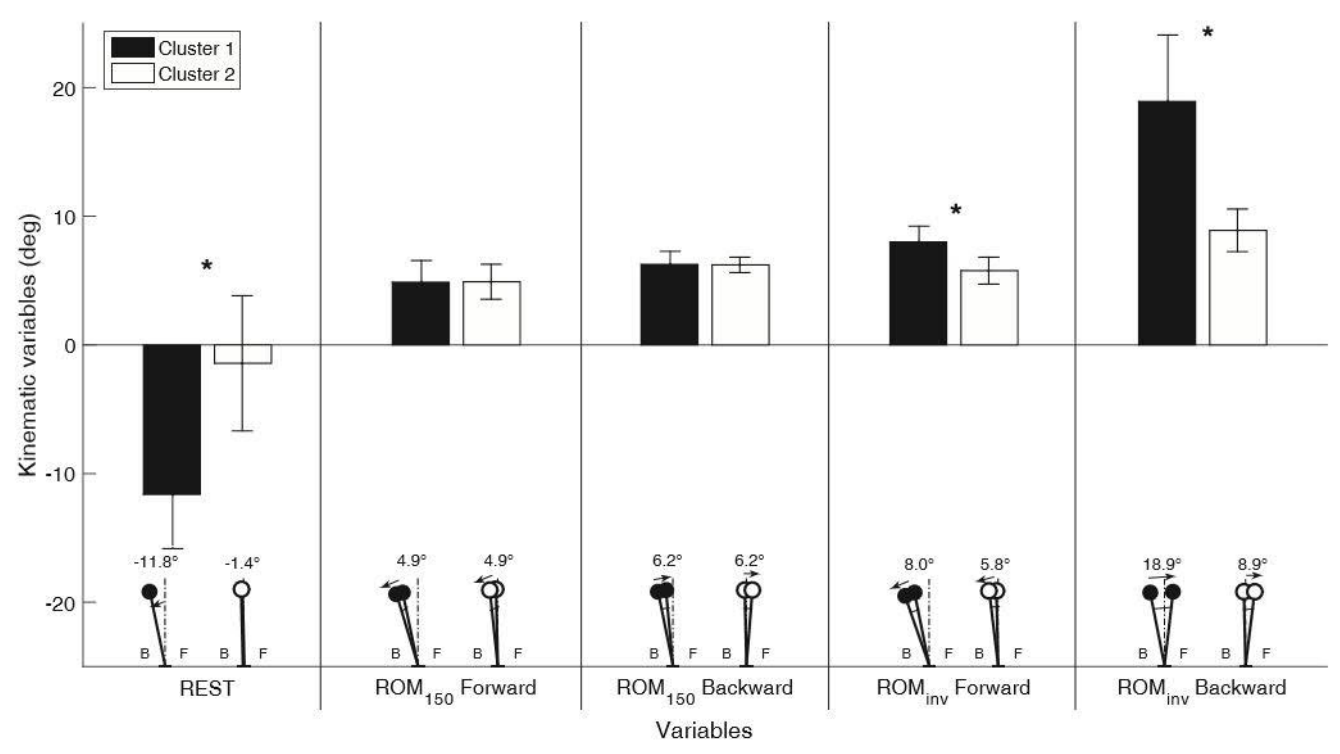

541

542 Figure 4. Kinematic variables. The trunk angle with respect to the vertical at rest (REST),

543 the trunk range of motion $150 \mathrm{~ms}$ after the shoulder acceleration $\left(\mathrm{ROM}_{150}\right)$ and trunk range of

544 motion when the trunk inverted the motion $\left(\mathrm{ROM}_{\mathrm{inv}}\right)$ in forward and backward perturbations

545 were reported in upper part of the figure using an histogram. Under the histogram an

546 illustration of REST, $\mathrm{ROM}_{150}, \mathrm{ROM}_{\mathrm{inv}}$ is reported for both directions and clusters. The letter

547 "B" stands for backward direction, whereas the letter "F" stands for forward direction. The

548 numbers reports the mean values for each variable. REST and $\mathrm{ROM}_{\mathrm{inv}}$ showed a difference

549 between the two clusters in both forward and backward perturbations (*). Cluster 2 (athletes

550 with low impact of impairment) had the trunk closer to the vertical at rest, whereas cluster 1

551 (athletes with high impact of impairment) showed an extended position for the trunk. Cluster

5522 had greater trunk ROM in both perturbation directions than cluster 1. Overall, backward

553 perturbation direction showed higher trunk ROM than forward direction. 